\title{
Help Desk Management System for PC Troubleshooting
}

\author{
Safiya Al-Sharji \\ Student, Computer Engineering \\ Caledonian College of \\ Engineering \\ Muscat, Oman
}

\author{
Ali Al-Mahruqi \\ Senior Lecture \\ Caledonian College of \\ Engineering \\ Muscat, Oman
}

\author{
Ramakrishna Kumar \\ Senior Lecturer \\ Caledonian College of \\ Engineering \\ Muscat, Oman
}

\begin{abstract}
"Help Desk Management System" is a software solution for PC troubleshooting in the work place. PC problems at the work place occur frequently. Such problems may negatively affect the employees work and reduce the workflow efficiency. Help desk teams sometimes find difficulty in rectifying these computer issues within a speculated time frame due to in experience staff or sometimes spending time on trouble shooting the previous similar type of problems.

The time required for help desk team members to solve all computer problems can be reduced by using Help Desk Management System that will enable sending and receiving PC complaints by employees and taking the backup of the trouble shooting information will allow the help desk team to handle the complaints effectively and efficiently.

This system meets the needs of information technology department by providing a number of features such as recording the solutions for future reference, text chat, send text messages, and so on.
\end{abstract}

\section{General Terms}

Helpdesk department, computer complaints, Remote desktop.

\section{Keywords}

PC, SQL. .Net.

\section{INTRODUCTION}

A Help Desk Management System is a software application that can provide quicker solutions for PC related problems that may face by employees of different departments during their working hours. This application facilitates the employees to post their PC related complaints directly to help desk team members. Help desk team will receive the posted complaints by the employees of all departments through this system. After receiving all complaints help desk team will consolidate them and priorities' the issues with the help of this application.

The system consists of three main processes which are a new incident, first processor and second processor. The first process new incident is used by the employees for registering their initial problem along with complete details of the problem. The details of the registered problems will be seen by help desk team members (Technicians) this stage is called as first processor. In this processor, the technician will try to solve the problem remotely from their PC by pressing on a "Remote desktop button" of the application. The function of this button is to connect the user PC with the Technician system remotely. In case the technician cannot solve the problem remotely, he will pass the complaint to the next phase which is called as second processor. The second processor is used by the help desk team members (Engineers) who will also try to solve the problem remotely. If they do not succeed, they will request another technician to solve the problem on site by sending an SMS to the other technician mobile phone through the developed application.

The purpose of using SMS contact is to inform the technician who works in another section and who are responsible for solving such problems on site. Thus able to solve the specific problem and to perform the entire requested task through a single interface in order to save time and reduce delay.

Therefore the importance of this system is to reduce the required time for solving each request received by the help desk team and enhance the performance of the workplace by facilitating the communication between employees from different departments and the help desk team members. Further, it helps employees in the IT department by providing different features such as text chat, sending SMS which is incorporated within a single system. These features are very useful to the IT department as it will simplify the troubleshooting to become much easier.

\section{LITERATURE REVIEW}

Anon [3], established the standard features that are needed to ensure quality of the best Help Desk Software. He stated that choosing the best Help Desk Software is very crucial since majority of employees will require a faster service with a sophisticated system. Choosing the wrong Help Desk Software that does not provide the standard features may cause problems currently and in future. A poor Help Desk Software may reduce effectiveness of the organization and causes time wastage. In the author point of view, the developer must include all the standards features in any of the Help Desk software in order to increase the effectiveness and productivity of the system. Below are the features suggested by Anon[3]

- "Identification and Tracking": allows the user (help desk team members) to identify the existing problem. This is a general feature that must be included in the most Help Desk software.

- "Store and Search": provide two methods of searching:

1. Based on the employee: this allows the user (help desk team members) to search for the issues which are related to specific employees.

2. Based on the solution: this allows the user (help desk team members) to search for solutions of the common issues within the organization. 
- "Tracking Communication with Employees": Save previous chats between the help desk team members and the employees of different departments which occur through the system. This is useful for following up the work of each help desk team members and for training future employees.

- "Team Collaboration":

In case if one of the help desk team members finds an issue with solving a specific problem this feature allows him to pass the problem to one who has more experience in solving complicated problems. This feature will also save time.

- "Meet Current and Future Needs": The system should be flexible so as to accommodate enough numbers of employees as the institution expanse, therefore increasing the overall staff figure.

- "Issue Status":

This feature allows clear information about the current state of the issues, especially problems which require attention in such aspects (spending more time). This feature will help to ensure that the issues are handled in time.

- "Prioritize Issues":

In case if there are multiple issues. The system will classify the issues and give the priority to the most important issues to be handled quickly. This will save the time and effort. The author indicates that this feature is not one of the must include features, but definitely it's a useful one.

The above features have given some idea and helped the developer to incorporate in the current application by fine tuning.

Anon [4], the Radmin proposed secure and reliable windows based remote control program. The Radmin allows the user to work on multiple computers through a single interface. Through the product the user (help desk team members) will be able to access the employee's computers remotely to solve the issues. The company produces a new version which known as Radmin3. This feature helps to solve the interaction problem between the help desk team members and the employees of different departments by providing text and voice chat techniques.

The feature of text and voice chat allows the help desk team members to solve the employee's computer problems while communicating with them through the chat.

The Radmin advantages by using the help desk team can be as follows:

- Response at the require time to the employee requests.

- $\quad$ Reduce the costs for the help desk team members. Because it is not necessary to solve the problem on the site if it's possible to handle remotely.

- Ability to access any computer from anywhere. The figure 2.2 below shows how the Radmin for the helpdesk looks and how access is done to the clients PCs.
According to, Anon [3], the above advantages are of the standard features and thus count as strengths in the system.

The system consist of varies features of which some of them are defined as standard features for the best help desk management system as established by, Anon [3],. Also there are extra features which can help the help desk team members to complete their work in time and thus increase their performance. This system can be as a very good, according to the provided features which meet the user needs.

There is another help desk management system that is used in some of the Malaysian ministries. The system is known as Secured Open Source Web Based Help Desk System. According to, Hasnan \& Dalbir [5], the system is an online Help Desk management system that was developed for the purpose of facilitating and manages the received issues from the different employees in the Malaysian governmental ministries. The system was developed by using PHP programming language and MySQL as the back end. The users are classified into three which are: Normal user, Supervisor, Admin. The system features are as follow:

- $\quad$ High Security.

- Ability to record all the incoming issues.

- Show the status of the issues by monitoring the progress of each issue.

- The ability to classify and distribute the received issues to the technical support staffs based on each member capability.

- Generate the reports to help the managerial decision making.

Most of the above system features are defined as standard features for the best help desk management system by Anon [3], such issue status, meet current and future needs, prioritize issues, team collaboration. Which actually defined as strengths of the system, but comparing to the Radmin system this feature can be categorized as strict system which follows the standard features and do not provide new features which may be useful for the users. The system has been developed to overcome the manual system and it's categorized as a very good system according to the huge number of workstations which are controlled and managed through it. But also this feature possesses some weakness where the number of users may increase in each year, so the system should be upgraded and update regularly to maintain its performance.

One of the most popular applications is TeamViewer. This software allows the user to control, run and work on other PCs remotely through the internet. Based on John [7], TeamViewer includes the service queue feature. This feature allows the IT support team to manage, share and assign support requests for immediate support.

Also the TeamViewer software includes other features such as: File sharing, Universal clipboard, Notifications.

The system consists some standard features of the best help desk management system such as solving the problem at the requested time, but generally Team Viewer proved features are useful for personal use because users can ask for help remotely by starting the session, but cannot send the complaint in detail, there is no complaint list, there are only two users who can connect remotely through the system, 
which means that the technician cannot pass the issue to the engineer to solve the problem in case of facing any difficulty in solving the problem.

Comparing to Radmin and Secured Open Source Web Based Help Desk System, the TeamViewer is developed to handle single issues at a time and cannot receive the issues from the employees of different departments; it has been developed for remote control purpose only. As that is the case, we can categorize the system as good and not suitable for all the problems of the help desk system.

Another product is UltraVNC. According to the developer's team [6], the UltraVNC is powerful and easy software that provides the ability of controlling other computers remotely through the internet or a LAN network. In case if any employee faces a problem on the computer this software allows the help desk team members to quickly access employee's computer from anywhere and solve the problem remotely. The software contains the key features such as: Encryption, File transfer and Chat features.

The above systems have some similar features such as transferring files and chat features. The other issue is a security feature which is included in the most four discussed systems. It is taken as a major feature that provides stability to the four discussed system. All of these systems are developed for the organization according to the provided features which meet the organization needs. In general all of these systems are able to monitor the status of the issue and prioritize based on the importance of the problem. If the problem requires an urgent solution, it will be marked as first priority which will be prioritized to be solved first. Monitoring and follow up the issue is another feature that is available in all of the four systems and it has helped the managers and supervisors to know the status of the problems on whether they have been solved or still pending. The major strengths which are different from the existing systems are as follows

1. Text Messages: This feature allows the employees to receive the message direct to their phone so as to indicate if the problems have been solved or not. Most of the existing systems do not have this feature, which we believe it is a unique feature to motivate the employees of the faster response to their problem.

2. Remote Desktop Connection: depending on the problem, the system allows the technicians to access the employee's computers remotely and solve their problem without going physically to their computers. This feature is unique compared to the existing systems whereby they have to visit the employee's office and solve their problems.

3. Problem recording for future reference: This is another good feature that allows the technician and employees to record the problems and the steps used to solve the problems. This will simplify the troubleshooting issue if similar problem persist for the second time.

\section{PROPOSED SYSTEM FRAMEWORK}

\subsection{Flowchart of the System}

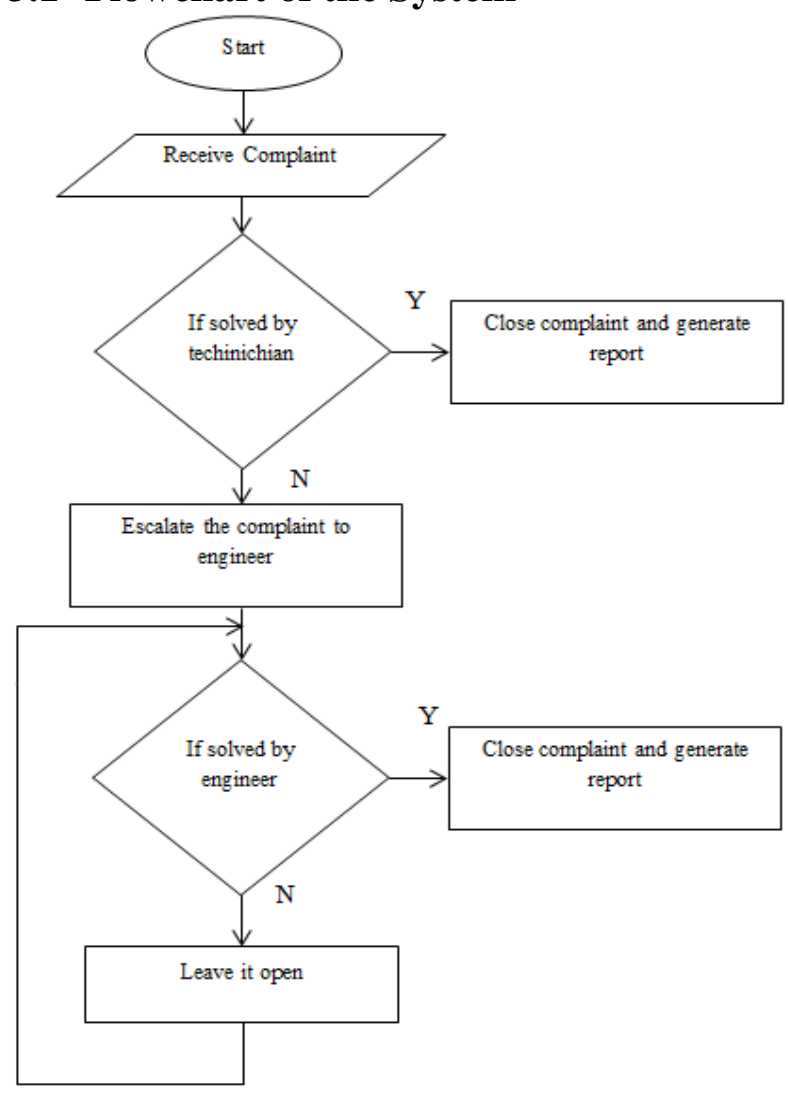

Fig 1 General Flowchart of the system

The above flowchart can be described with a help of algorithm as below:

1. Start the program.

2. Receive the complaint from an employee.

3. If the complaint is solved by the technician, close the complaint and generate a report otherwise, go to step 4.

4. Escalate the complaint to engineer.

5. If the escalated complaint solved by the engineer, close the complaint and generate a report otherwise, go to step 6.

6. Leave the complaint open to be solved by another engineer and go to step 5.

\subsection{Initial Design of the Forms}

The system consists of various forms; each form is designed for a different purpose and used by different user. The initial design is only a planned design in order to imagine the final design of the system with respect of user requirements in each form.

Fig 2 First Processor Initial Form

The above form shows the planned design for the first processor form that is designed to be used by the technicians. Here the technician should be able to receive the sent 
complaint and solve the issue by pressing on a remote access button which automatically connects to the windows remote desktop. Also the technician can get more details about the received complaint through the text chat. The received complaint will be classified based on the priority where the first priority complaint should be handled first, to avoid the inconvenience that can occur by delaying the urgent problems.

They're also other forms such as second processor, login, new user, change password which will be shown in the design part of the system.

\section{DESIGN AND IMPLEMENTATION}

\subsection{ER Diagram}

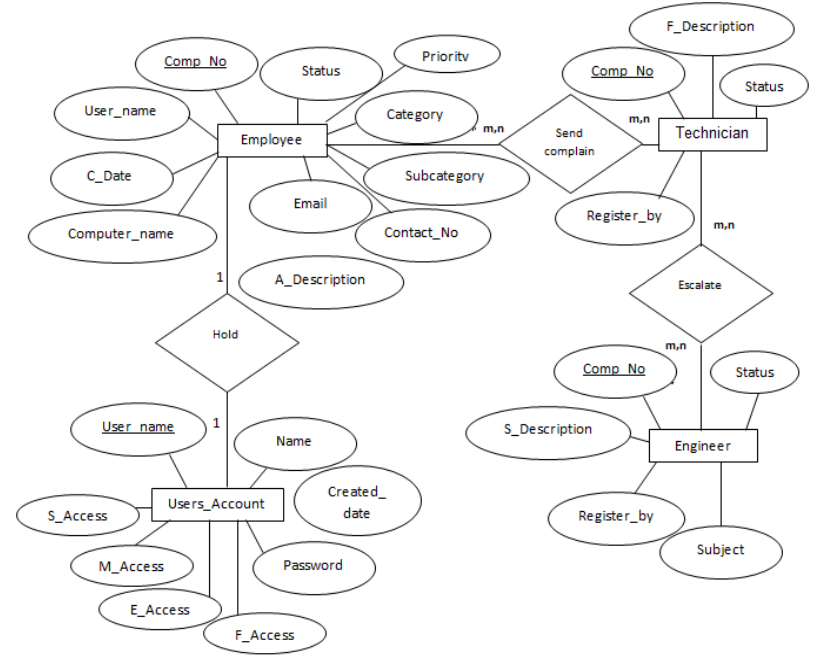

Fig 3 ER Diagram

The relationships between the entities can be described as follows:

- Employee and technician (Many to Many): Many employees can send many complaints and many technicians can receive many complaints.

- Technician and engineer (Many to Many): Many technicians can escalate many complaints and many escalated complaints can be received by the engineers.

- Employee and user account (one to one): Each employee can have one account and each user account hold only one employee accounts.

\subsection{The Created Tables in the DB}

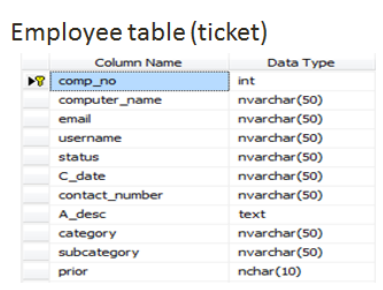

Technician table (Ftier)

Engineer table (Stier)

\begin{tabular}{|l|l|}
\multicolumn{1}{|c|}{ Column Name } & \multicolumn{1}{c|}{ Data Type } \\
\hline comp_no & int \\
\hline subject & nvarchar(50) \\
\hline s_desc & nvarchar(MAX) \\
\hline status & nvarchar(50) \\
\hline registeredby & nvarchar(50) \\
\hline sdate & nvarchar(50) \\
\hline
\end{tabular}

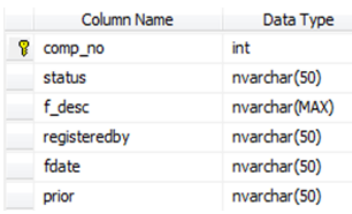

Users Accounts table

\begin{tabular}{|l|l|}
\multicolumn{1}{|c|}{ Come } & \multicolumn{1}{c}{ Datumn Name Type } \\
nuarchar(50) \\
nusername & nvarchar(50) \\
password & nvarchar(50) \\
\hline created_date & nvarchar(50) \\
\hline M_Access & bit \\
\hline E_Access & bit \\
\hline F_Access & bit \\
\hline S_Access & bit \\
\hline
\end{tabular}

Fig 4 Created Tables in DB

There are 4 main tables are created in the DB as shown in the above figure. Employee table is created to store and extract the employee complaint details, technician table is created to store and extract the complaint details that escalate or solved by a technician, Engineer table is created to store and extract the complaint details that passed or solved by the engineer, User account table is created to store and extract the user information. Each of the created table consists of different columns based on the require data.

\subsection{System Design}

The design part of the system is accomplished in vb.net. The system consists of a number of interfaces such as login, new user, second processor, first processor and so on. The below figure shows the login form which is designed for security purpose. Here only the authorized user will be able to access into the system.

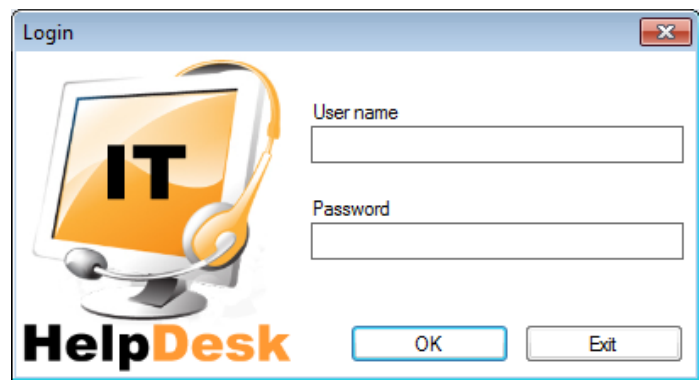

Fig 5 Login Form

There is also a first processor form which is used by the technicians. Through this form the technician will know the history of complaint and they will trouble shoot the problem remotely by pressing on connect to remote desktop button and if any further details of the issue is required the technician, he/she can start text chat with employee. In case that the problem cannot be solved, then the technician can escalate the complaint to the engineer through selecting escalate in the state's list. The design is shown as follows. 


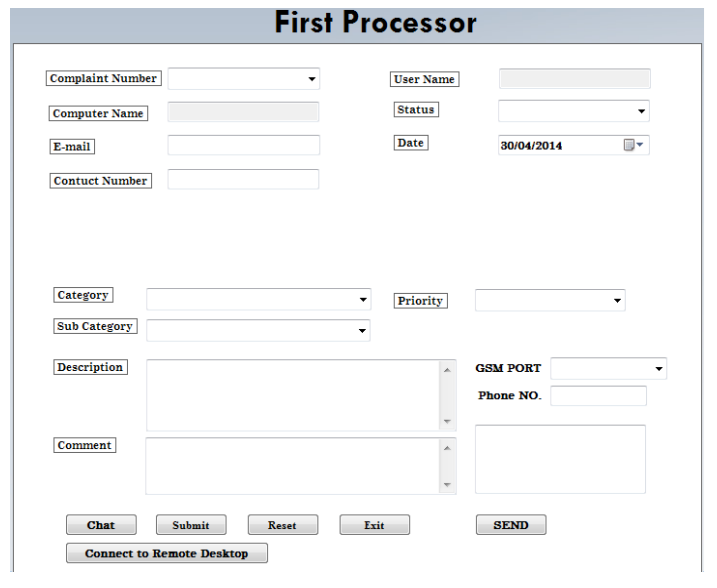

Fig 6 First Processor Design

The second processor is designed to be used by the engineers. The engineer receives complaints from the technician and tries to solve remotely if it is possible, otherwise will send an SMS to other technician to solve it on site. Second Processor interface is shown below:

\section{Fig 7 Second Processor Design}

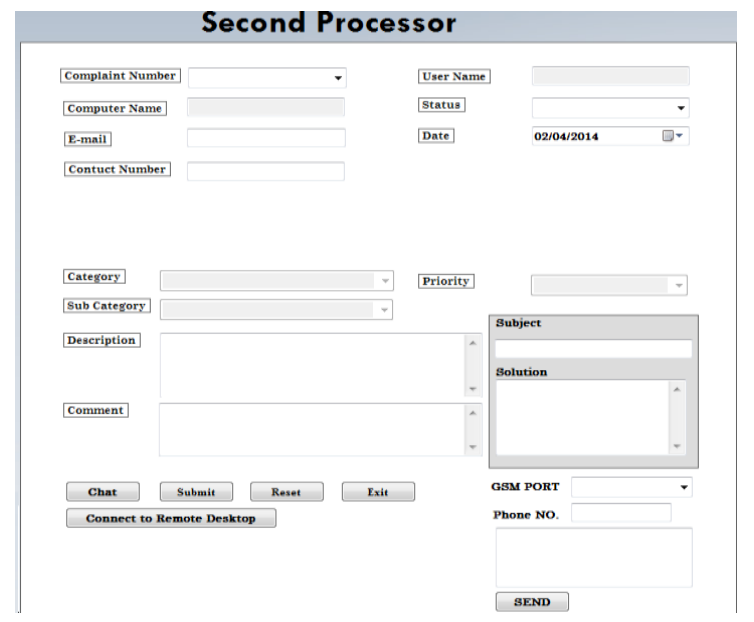

Fig 7 Second Processor Design

Once the problem is solved the system will generate a report to the manager in order to facilitate the manager follow-up tasks. The report form design is shown below:

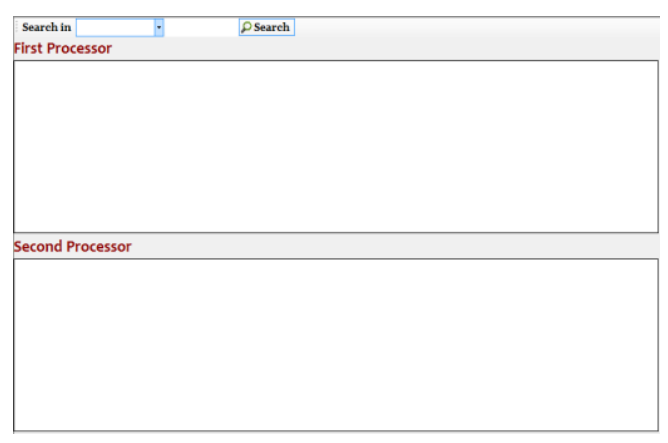

\subsection{Implementation}

The first step of implementation part is to establish the connection between the SQL server and Vb.net. This task is performed by using the connection tools that are supported by Microsoft such as ADODB (Active Data Object) and OLEDB (Object Linking Embedding). The following code is used for connection in order to extract and store the data in DB:

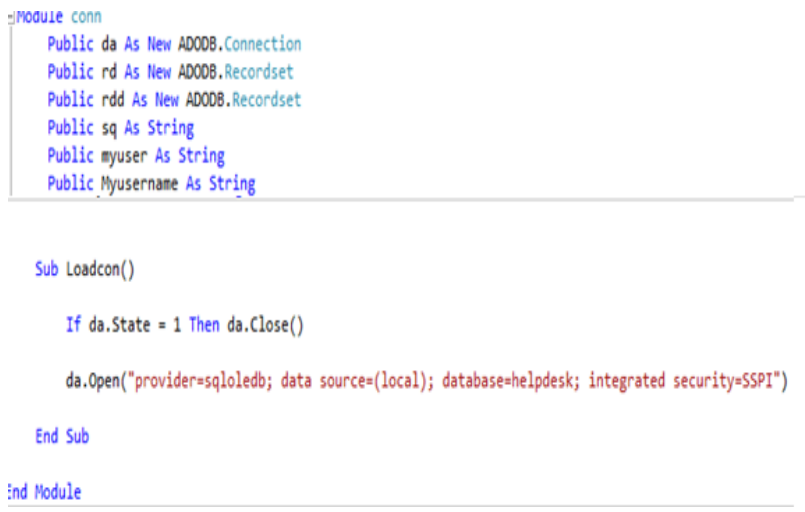

Fig 9 Establish the Connection Code

The above code is written in module. Also have to add a reference which is Microsoft ActiveX data object which is 6.1 .

The system is programmed by using many codes but the following are some of the used code:

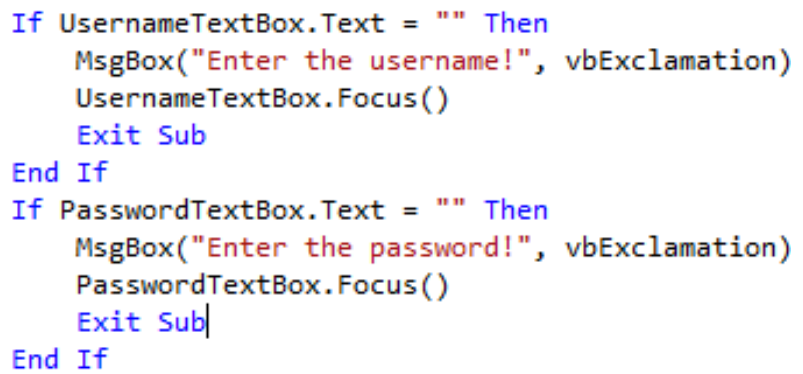

Fig 10 Login Code

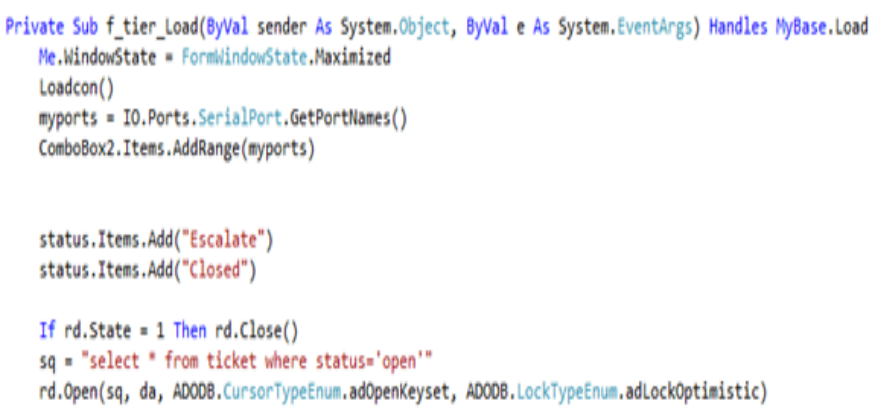

Fig 11 first processor code

The above code is used to display the data once the technician opens the form. The program will look for the complaints which are not solved in the database and added into a complaint number list.

Fig 8 Report Design 


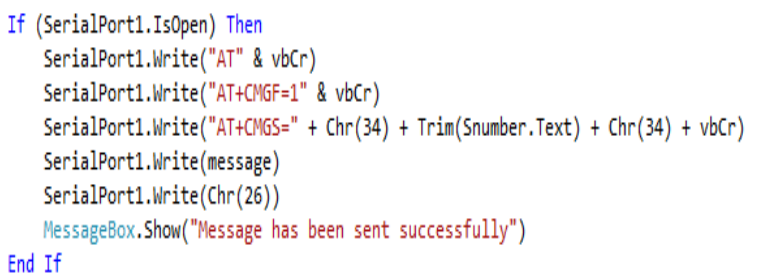

Fig 12 Sending SMS Code

The above code is used for Sending SMS. The code checks for serial port availability if it is available then it opens the port then starts to gain the attention of USB modem in order to start sending SMS. A portion of the above code also selects the mode of sending SMS and to identify the number of mobile phones that are ready to send SMS.

\section{RESULT ANALYSIS}

The system is programmed successfully by using VB.net All the features of this objectives has been achieved and working without any problem. The integration of visual basic and SQL server has provided an outstanding result which enables all the features to function correctly.

The main successful feature of this system is that, it allows the employee to contact the technicians by different means which include recording and prioritize the problem in order to be solved with extra attention. Moreover it allows the technician and employees to chat and SMS directly in order to simplify the problems. Remote desktop login from the technician to the employees has successfully operated provided that the employee and technician's system has two ways credentials and remote desktop enablers.

The connection between visual basic and SQL server is performed successfully by following steps:

- Create the require tables in the SQL server. Each of created tables involved specific attributes.

- Create a module in the visual basic and write the require code for establishing connection between the VB.net and SQL server. The figures below show the data extract and store from and into DB successfully

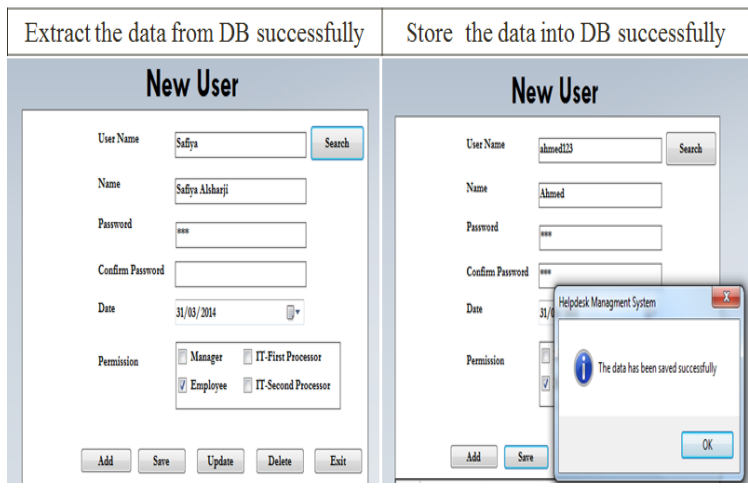

Fig 13 Extract and Store Data
The system generates the report successfully for the IT Head. The IT Head can search for the generated report based on user name or complaint number. The figure below shows the report generated by a system:

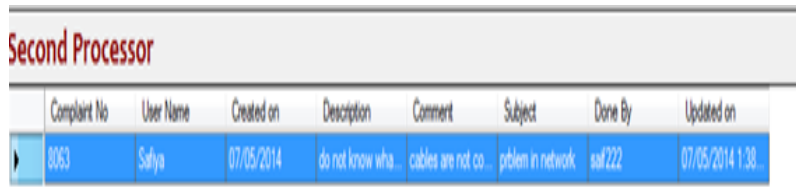

Fig 14 Generated Reports

The system has successfully provided a path link from the helpdesk to remote desktop wizard of the employee's computer. Whenever an employee sends a complain to the technicians, the remote desktop button "Connect to remote desktop" appears on the complains wizard of the employee which will allow the technicians to connect via the IP address.

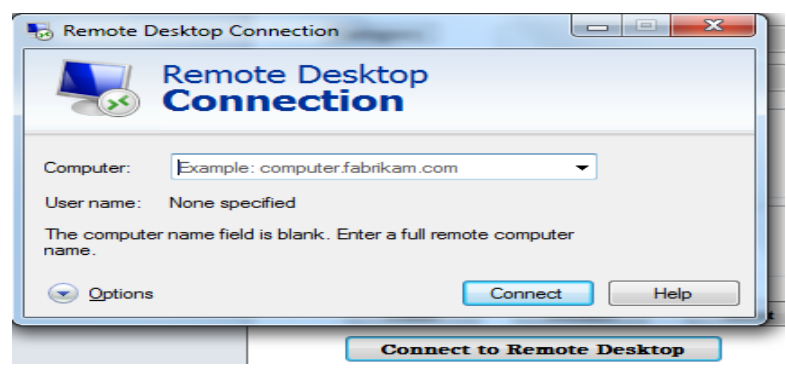

Fig 15 Remote Desktop Connection

The system is able to facilitate the communication between the employees of different departments and help desk team members through providing SMS and text chat features. Employees can chat directly to the technicians by using chat rooms or SMS which is directly linked to the system. The technician can use the wizard provided by the system and use GSM number of the employee which in turn allows the employees to flexibly use their mobile phone when they are away from their desk.

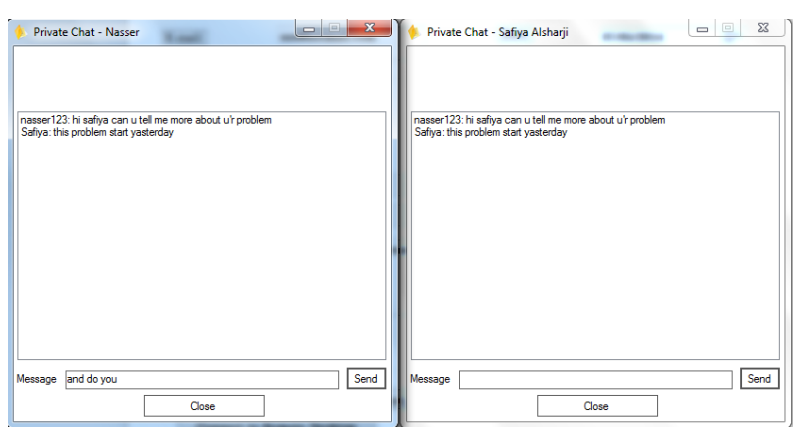

Fig 16 Text Chat 


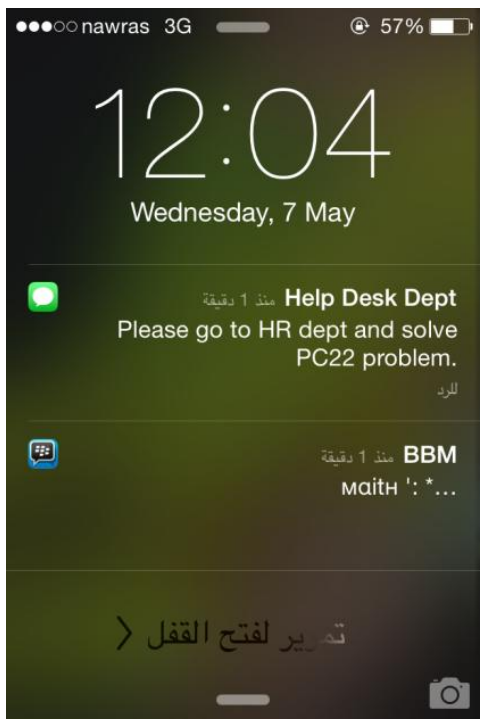

Fig 17 Received Messages

The system is able record the problem for future reference details are recorded in the database successfully to be used in the future; this feature is reducing the time of solving the repeated issues by checking the recorded problem.

The system follows some of the standard features such as Identification and Tracking, Store and Search, Team Collaboration, Issue Status, Prioritize Issues and Meet Current and Future Needs. These features are accounted as strength of any help desk management system.

\section{CONCLUSION}

This paper presents a helpful system in workplaces that reduce effort, increase performance, and facilitate the communication between the help desk team members and the employee of a different department. The system consists of different forms that are used by different users such as engineer, technician and manager. The system programmed with a number of features such as sending SMS, text chat, complaint classification, and so on. Also the system includes some of the standard features such as issue status, issue priority, store and search which count as the strengths from other systems. The system has been designed and developed based on the standard of the organization requirements. The system has programmed successfully by using vb.net and connected to the SQL server in order to extract and store data.

\section{Future Work}

The help desk management system for computer troubleshooting can be upgraded in the future in order to enhance and meet the new user requirements by adding supplementary features such as video and voice chatting between the help desk team members and the employee who send the complaint in order to help in obtaining more details about the specific complaint sent by the employees. The system will make use of Virtual private network (VPN) technology instead of remote desktop connection so as to allow better flexibility and security.

\section{ACKNOWLEDGMENT}

The author would like to thank each individual who helped during the development of this project. Special thanks go to my guide who gave me superlative comments until the completion of this project. Last but not least, I would like to thank all my family members for their support and encouragement during the entire period of my project.

\section{REFERENCES}

[1] Cory,J.,2010. Help Desk technology. Techopedia. Single processing, 2(1),pp 20-29. Available at: http://www.techopedia.com/definition/353/help-desk. [Accessed 20 November 2013]

[2] Margaret,R.,2005. Help Desk. IEEE trans. Searchcrm,54(3),pp 100-120. Available at:http://searchcrm.techtarget.com/definition/help-desk [Accessed 15 November 2013]

[3] Anon, 2011. What Your Company Should Look for When Conducting a Help Desk Software Review. Computer Technology, 3, p1-3

[4] Anon, 2012. Most popular remote control software in the world. Redmond Magazine, 13, p11-19

[5] Hasnan,O \& Dalbir,S., 2011. Secure Open Source Web Based Helpdesk System. Journal of Theoretical and Applied Information Technology, 31, p1-4

[6] Robert, G., 2009. Help Desk. Component Developer Magazine, 22, P14-19

[7] John, C., 2013 TeamViewer new technology. Business wire, 33, p25-28 